\title{
RELATOS DE PESQUISAS \\ A EFETIVIDADE INFORMACIONAL DOS PORTAIS DE TRANSPARÊNCIA GOVERNAMENTAIS NA PERSPECTIVA DO CIDADÃO
}

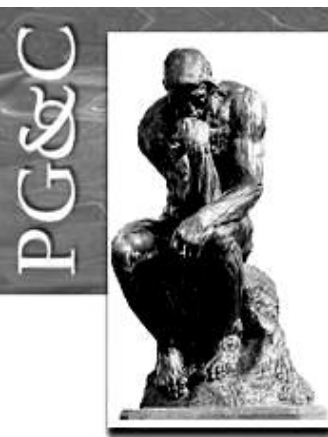

\author{
Maciel Carlos Antunes \\ Mestre em Administração pela Universidade de Brasília, Brasil. Professor \\ do Centro Universitário IESB, Brasil. \\ E-mail: $\underline{\text { m.carlosantunes@gmail.com }}$
}

Resumo

Desde o surgimento da nova administração pública até as mudanças mais recentes, muito se debateu sobre transparência, participação e controle social. Os órgãos públicos, visando disponibilizar informações gerenciais, criaram, em seus portais na internet, o menu de transparência. Assim, questiona-se se as informações disponibilizadas promovem efetividade informacional em suas dimensões - acesso, conteúdo, estrutura e valor e, adicionalmente despertam o interesse da participação social. O objetivo do estudo é verificar se os dados postados atendem às preferências dos cidadãos e despertam nestes o interesse em participar das decisões políticas. Neste trabalho, optou-se por utilizar a Teoria da Comunicação aliada à tese da administração democrática no âmbito do conceito de "governo aberto". Trata-se de pesquisa descritiva com abordagem quantitativa, aplicação de questionário on-line e análise comparativa de dados. Os resultados indicaram que: as organizações não disponibilizam $100 \%$ das informações sugeridas nos normativos; em contexto geral a navegabilidade, usabilidade e acessibilidade são razoáveis e os sítios do Poder Executivo e dos Estados Federados possuem as piores avaliações; as informações disponibilizadas são parcialmente relevantes e de fácil entendimento e seu volume não é satisfatório; as informações disponibilizadas não atendem às necessidade de conhecimento dos usuários e não despertam o interesse em participar do processo de tomada de decisão; e, as informações promovem parcialmente o princípio democrático da transparência. Ao final, concluiu-se que as informações postadas pelos órgãos públicos não possuem efetividade suficiente para atender ao princípio da transparência, bem como deve-se buscar o planejamento da comunicação pública de forma ampla.

Palavras-chave: Governo Aberto. Menu Transparência. Teoria da Comunicação. Administração Pública Democrática. Efetividade Informacional.

\section{INFORMATIONAL EFFECTIVENESS OF THE TRANSPARENCY PORTALS}

\begin{abstract}
Since the movement of the new public administration until the recent changes much has been discussed about transparency, social participation and control. The public agencies to provide managerial information created in your portals. Thus, it's questioned if the information promotes informational effectiveness (perspectives: access, content, structure and value) and, in addition, arouse the interest of social participation. The purpose of this study is to verify that the data posted by agencies meet the preferences of the citizen, and, if the interest to participate in the political decisions is aroused. The essence of this discussion rests largely part on the thesis of democratic administration, and, the concept of open government. It's a descriptive research with quantitative approach and use online questionnaire and comparative data analysis. In the end, it was identified that the information posted by public agencies is not effective enough to comply with the principle of transparency. The results indicated that: organizations do not provide $100 \%$ of the information suggested in the regulations; in general, navigability, usability and accessibility are reasonable and the sites of the Federal Government and the States have the worst evaluations; the information provided is partially relevant and easy to understand and its volume is not satisfactory; the information provided don't meet the needs of society and does not arouse interest in participating in the decision-making process; and the information partly promotes
\end{abstract}

Perspectivas em Gestão \& Conhecimento, João Pessoa, v. 8, n. 2, p. 162-178, mai./ago. 2018. DOI: http://dx.doi.org/10.21714/2236-417X2018v8n2p162

http://periodicos.ufpb.br/ojs2/index.php/pgc. ISSN: 2236-417X. Publicação sob Licença (cc) EY-NC-ND 
the democratic principle of transparency. In the end, it was concluded that the information posted by the public agencies does not have sufficient effectiveness to comply with the principle of transparency, as well as the planning of public communication in a broad.

Keywords: Open Government. Sites of Transparency. Theory of Communication. Informational Effectiveness Perspective.

\section{INTRODUÇÃO}

A questão da transparência governamental é tema de discussão não somente nas universidades e associações, mas, também, no próprio governo. A democratização e as reformas administrativas conduziram à abertura dos dados e das informações a fim de assegurar a eficiência dos princípios da boa governança e de dotar a administração de legitimidade.

Dessa forma, foram editadas diversas normas regulamentadoras da abertura dos dados governamentais, em especial no que diz respeito à Lei de Acesso à Informação (Lei no 12.527/2011). O meio utilizado pelo governo para prestar as informações é a internet, via sítios de diversos órgãos públicos. Definiu-se um padrão de informações que promove a transparência e os dados foram disponibilizados.

Os portais de governo se tornaram responsáveis pelo fluxo informacional produzido pela gestão pública e disponibilizado aos cidadãos. Por intermédio desses portais, os governos mostram sua identidade, seus propósitos e suas realizações, a partir da concentração e disponibilização de serviços e informações, possibilitando o aumento da transparência e de participação da sociedade nas ações governamentais (PINHO, 2008).

Com a introdução do acesso à informação organizada por normatização federal e com a existência de portais de governo capazes de suportar o fluxo informacional necessário, voltase a atenção para a efetividade informacional, haja vista que, nos fluxos informacionais, trafegam dados e informações que contribuem para a construção de conhecimento dos indivíduos e das organizações (SANTOS; VALENTIM, 2014).

Este estudo foi organizado em torno de quatro questões: a primeira questiona o acesso - o acesso às informações e a navegação no menu Transparência são simples e descomplicados?; a segunda questiona a estrutura das informações - as informações fornecidas são de fácil entendimento?; a terceira questiona o conteúdo das informações - as informações fornecidas atendem ao anseio dos indivíduos?; e a quarta questiona o valor das informações - as informações fornecidas são capazes de despertar interesse na gestão da organização?

Tendo isso em vista, o objetivo do estudo é verificar se os dados postados atendem às preferências dos cidadãos e despertam nestes o interesse em participar das decisões políticas.

A sustentação teórica se dá com a Teoria da Comunicação, com a discussão dos princípios democráticos de transparência e governo aberto. A pesquisa possui característica descritiva com abordagem quantitativa e com aplicação de questionário on-line e análise comparativa de dados.

O assunto abordado é relevante para a administração pública, haja vista os esforços que esta realiza para promover a transparência. A principal contribuição deste trabalho reside na discussão da aceitação e utilidade das informações fornecidas. Embora a pesquisa seja descritiva, ela acrescenta à literatura por meio da exposição de fatores associados à demanda pública de transparência que remetem à governança democrática.

Perspectivas em Gestão \& Conhecimento, João Pessoa, v. 8, n. 2, p. 162-178, mai./ago. 2018. 


\section{REFERENCIAL TEÓRICO}

\subsection{Comunicação e Informação}

O meio utilizado pelos órgãos do governo federal para divulgação dos resultados de suas ações para o cidadão é a comunicação via website. Essas informações estão consolidadas e publicadas com a denominação "Transparência" nas páginas da web das organizações.

Shannon e Weaver $(1964$, p. 3) utilizaram a palavra "comunicação" em seu estudo em sentido amplo, ou seja, incluíram, no termo, todas as formas pelas quais as mensagens são levadas de uma pessoa a outra, envolvendo o "discurso escrito e oral, a música, as artes pictóricas, o teatro e, na verdade, todo o comportamento humano". Para tanto, desenvolveram o diagrama esquemático abaixo.

Figura 1 - Diagrama esquemático: sistema geral de comunicação

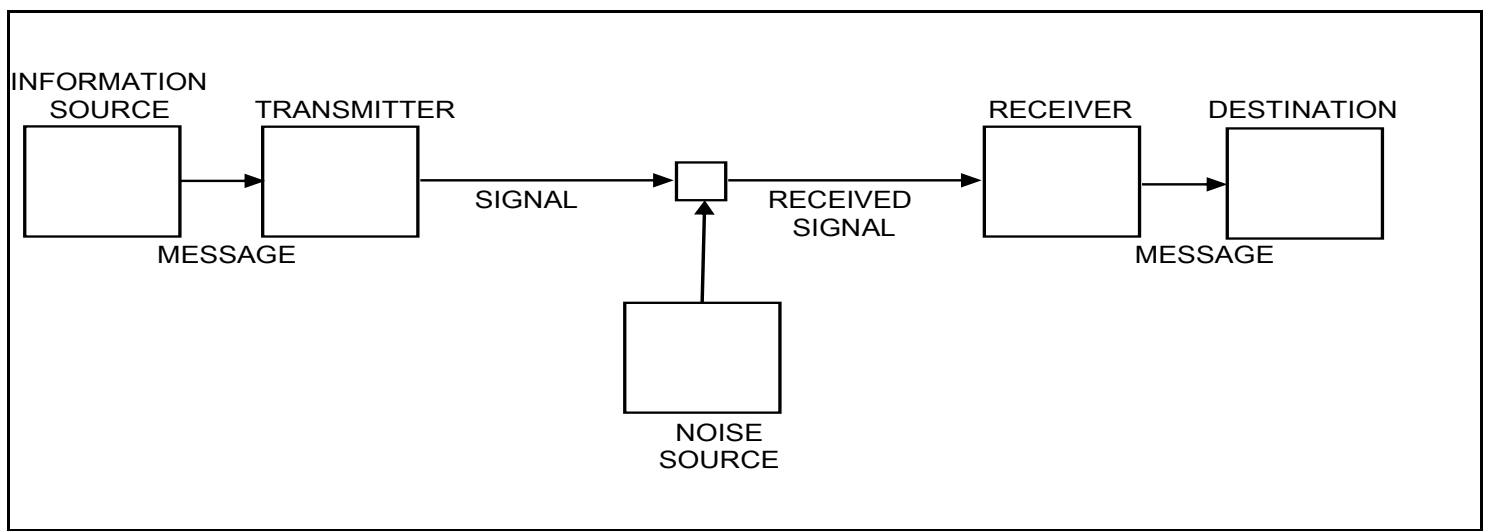

Fonte: Shannon e Weaver (1964, p. 7).

Segundo os autores, "o problema fundamental da comunicação é o de reproduzir em um ponto exatamente ou aproximadamente uma mensagem selecionada em outro ponto" (SHANNON; WEAVER, 1964, p.31). Eles discutem três níveis de problemas que ocorrem nas comunicações. Para efeito deste estudo, porém, apresenta-se apenas o terceiro nível: a efetividade da comunicação, ou seja, de que maneira, efetivamente, a mensagem recebida afeta a conduta do receptor na forma desejada.

Vishwanath e Kaufmann (1999) atestam que a comunicação efetiva gera alto desempenho e vantagem competitiva e indicam que há elevada riqueza de comunicação quando esta é transmitida face a face ou eletronicamente. Para que a comunicação adquira a condição de efetiva, os autores descrevem alguns atributos necessários: completude e clareza; facilidade para entendimento e interpretação; codificação em símbolos inteligíveis; adequado meio de transmissão - atenção ao nível de riqueza necessário para a informação; e utilização desse meio pelo receptor.

Nesse contexto, Araújo (1999) associa "informação" a "cidadania" sob o prisma político e conclui que a informação possibilita a criação de espaços sociais de cidadania e de transformação, sendo que esse movimento se inicia na prática informacional da recepção, "ou seja, a recepção é uma ação que pode transformar internamente o sujeito cognitivo-social" (ARAÚJO, 1999, p. 158).

Em contexto abrangente, entende-se que o objetivo do governo quando publica suas ações e realizações é fomentar o controle social, a transparência e a participação social. Para tanto, é necessário fornecer informações efetivas, que transformem o cidadão em agente

Perspectivas em Gestão \& Conhecimento, João Pessoa, v. 8, n. 2, p. 162-178, mai./ago. 2018. 
social e fiscalizador ativo. Um dos requisitos básicos para a participação democrática, segundo Gomes (2005, p. 59) seria

[...] volume adequado de conhecimento político estrutural e circunstancial, um estoque apropriado de informações não-distorcidas e relevantes, suficientes para habilitar o cidadão a níveis adequados de compreensão de questões, argumentos, posições e matérias relativas aos negócios públicos e ao jogo político.

Assim, a comunicação é utilizada para dar efetividade aos princípios democráticos de publicidade e transparência na administração pública. Piotrowski e Van Ryzin (2007) entendem que o acesso à informação é o componente central da transparência governamental e a transparência governamental é uma ferramenta para se alcançar accountability.

Especificamente, quanto à comunicação pública no âmbito governamental, aqui definida como comunicação pública estatal, tem-se que esta deve promover a interação entre governo e sociedade de forma a gerar à democracia participativa. Nesse sentido, utiliza-se o conceito de "comunicação pública" de Matos (2011 apud Kunsch, 2012, p. 17): "Referindo-se a normas, princípios e rotinas a comunicação social do governo, explicitadas ou não em suportes legais que regulamentam as comunicações internas e externas do serviço público". Jaramillo (2012, p. 2) acrescenta a relação da comunicação estatal com os anseios sociais: "[...] primeiro carrega a noção de comunicação associada a compreensão da coisa pública; segundo, opera em diferentes cenários, estado, política, organização e meios de comunicação; terceiro relaciona-se a princípios de transparência, inclusão e participação".

Discutindo os canais de comunicação, Loisier e Cossette (1993) asseveram que tais canais constituem a base para que os cidadãos possam seguir as ações do Estado e conhecer seus direitos. Ao presente estudo, interessa a comunicação informativa e mobilizadora, que se refere à adequada circulação da informação (JARAMILLO, 2012); à combinação de meios que garantam a integralidade, suficiência, qualidade e socialização da informação; e à criação de espaços de participação social, de compartilhamento de vontades para resolução de problemas sociais e de construção da cidadania.

Loisier e Cossette (1993) ensinam que a função da comunicação se estende à descoberta de dados ambientais. A relação bidirecional administração/ambiente possui valor estratégico primário e as informações do ambiente para a administração pública são determinantes para se definirem, com precisão, as expectativas do público como cliente no que se refere a serviços, programas ou projetos.

Jaramillo (2012) relata cinco problemas de comunicação nas entidades públicas: a concepção que as entidades têm de comunicação, resistência a mudanças, ausência de cultura de informação, falta de clareza nas relações com os meios de comunicação e enquadramento funcional dos servidores da instituição.

\subsection{Administração pública democrática}

Os princípios da administração pública descritos no art. 37 da Constituição Federal de 1988 são: legalidade, impessoalidade, moralidade, publicidade e eficiência. De forma precípite, o § 3으, inciso II determina que a publicidade dos atos, programas, obras, serviços e campanhas dos órgãos públicos tenha caráter educativo, informativo ou de orientação social. Quanto à participação social na administração pública, principalmente no acesso a registros administrativos e informações sobre atos do governo, o mesmo artigo atribui essa obrigação à lei futura (BRASIL, 1988).

Perspectivas em Gestão \& Conhecimento, João Pessoa, v. 8, n. 2, p. 162-178, mai./ago. 2018. 
A regulamentação ocorreu com a publicação da Lei № 12.527, de 18 de novembro de 2011, a Lei de Acesso à Informação. A União e o Ministério Público da União regulamentaram, internamente, a transparência via normativos próprios.

A abertura democrática, para Curtin e Mendes (2011), é um conceito mais amplo. Trata-se da capacidade dos cidadãos de acompanharem e influenciarem os processos administrativos a partir da divulgação de informações e do acesso às instâncias decisórias. Os princípios democráticos da transparência e da participação são considerados pilares da democracia administrativa. Assim, temos como conceituação que a transparência diz respeito à possibilidade de se conhecer o processo decisório das organizações públicas, enquanto a participação trata da possibilidade de se fazer parte desse processo, influenciando-se na tomada de decisão.

O princípio da transparência encontra-se regulamentado administrativamente e trata, basicamente, do fornecimento de informações sobre organização institucional, ações e programas, auditorias, participação social, convênios, receitas e despesas, licitações e contratações, relatórios de gestão, gestão de pessoas e, por fim, planejamento estratégico (BRASIL, 2012, 2015, 2016).

Contrariamente, o princípio da participação não é disciplinado administrativamente e ocorre em momentos esporádicos, via consultas públicas, fóruns com experts, orçamento participativo e reuniões comunitárias. Contudo, sem nenhum caráter de legalidade e/ou obrigatoriedade de influenciar o processo decisório, a exemplo do art. 48 da Lei Complementar 101/2000: "Parágrafo único. A transparência será assegurada também mediante: I - incentivo à participação popular e realização de audiências públicas, durante os processos de elaboração e discussão dos planos, lei de diretrizes orçamentárias e orçamentos".

Acredita-se que a participação civil no processo administrativo ocorra de forma mais acentuada quando realizada por grupos organizados, como conselhos de classe, associações e sindicatos.

A representação de interesses se concentra principalmente no acesso de organizações que representam as preferências dos seus componentes e que buscam não só influenciar a tomada de decisões que afetam os interesses que representam, mas, também promovê-los na política comunitária. (CURTIN; MENDES, 2011).

Questão não menos importante diz respeito à definição do tipo de informação que o cidadão deseja. Deve-se levar em consideração que os cidadãos possuem desejos e interesses por transparência diversos. Piotrowski e Van Ryzin (2007) defendem que o nível e tipo apropriado de transparência governamental continua a ser uma questão de controle não só entre os peritos, mas entre os cidadãos comuns, e que pouco esforço sistemático tem sido dedicado à medição da demanda de transparência governamental entre o público. Além disso, pouco se sabe sobre quais fatores podem influenciar esse desejo de transparência governamental.

Assim sendo, é possível que o cidadão tenha maior interesse em conhecer os resultados das políticas públicas do que os gastos realizados, ou prefira saber sobre o nível de redução do desemprego em vez de conhecer a estrutura das organizações. O interesse pode ser por objetivos futuros, e não por informações sobre licitações realizadas.

Com a inserção desses conceitos democráticos na administração pública cotidiana e com a abertura necessária para a prática da transparência e participação do cidadão nas decisões governamentais, os países criaram o sistema de governo aberto, com o propósito de tornar realidade esses princípios de boa governança.

Perspectivas em Gestão \& Conhecimento, João Pessoa, v. 8, n. 2, p. 162-178, mai./ago. 2018. 


\subsection{Governo Aberto}

A construção do governo aberto, fomentada pela Organização para a Cooperação e Desenvolvimento Econômico (OECD), deriva dos princípios da boa governança. Caddy e Vergez (2003), Curtin e Mendes (2011) e Calderón e Lorenzo (2010) elencam como principais princípios a abertura, a transparência e a accountability, os quais, em síntese, propõem que os poderes públicos escutem os anseios da sociedade, forneçam informações convenientes e eficientes e responsabilizem os agentes públicos por seus atos.

O governo aberto se sustenta em três pilares: transparência, participação e colaboração. Dessa forma, permite ao cidadão conhecer os processos governamentais e seus resultados - informação; recebe opiniões e sugestões do cidadão que declara interesses e preferências - colaboração; e as colaborações são consideradas para a construção de políticas públicas e tomadas de decisão - participação (CADDY; VERGEZ, 2003; CALDERÓN; LORENZO, 2010).

Estudos indicam os diversos benefícios da implantação do governo aberto: eficiência, redução da corrupção e aumento da legitimidade governamental; participação cidadã, reorganização de processos administrativos e melhoria das relações entre governo e cidadão; fiscalização mais eficaz, melhoria dos serviços oferecidos, aumento da satisfação dos cidadãos e melhoria do processo de tomada de decisão (CALDERÓN; LORENZO, 2010; MEIJER; CURTIN; HILLEBRANDT, 2012; ORTA, 2010).

$\mathrm{O}$ governo brasileiro aderiu aos princípios do governo aberto. Atualmente, atua em seu 2ํ Plano de Ação, de 2013, e está elaborando o 3 Plano. A participação social foi assegurada permanentemente a partir do portal e-Democracia e por intermédio do sítio do Ministério da Transparência e Controladoria-Geral da União. Nesse plano, estão previstas 52 medidas de transparência e governo aberto subdivididas em cinco eixos: gestão mais efetiva dos recursos públicos, aumento da integridade, melhoria dos serviços públicos, aumento da responsabilidade corporativa e criação de comunidades mais seguras.

Dois argumentos merecem destaque quando se discute o governo aberto: o primeiro diz respeito à informação e participação e, o segundo, à adequação da informação disponibilizada.

Meijer, Curtin e Hillebrandt (2012) defendem que os cidadãos devem ter informações sobre a gestão das organizações públicas. A possibilidade de se emitirem opiniões sobre essa gestão (vision and voice), assim, ocorreria de forma prática. Trata-se da relação entre transparência da informação e participação social. Os autores elencam três tipos de relação: a primeira e ideal é a relação sinergística, na qual a transparência assegura o acesso à informação sobre o governo e a participação faculta o acesso; a segunda é a relação complementar, utilizando-se da cidadania ativa realizada a partir da transparência; e a terceira, na qual se identificam impactos negativos entre informação e participação, é a relação enfraquecida. Nesta, o grau de abertura é limitado pela transparência.

Para Piotrowski e Van Ryzin (2007), o nível de interesse por transparência é diferente entre os indivíduos. Alguns possuem mais necessidade de informações, enquanto outros são menos interessados. Além disso, os tipos de informação que se pretende acessar diferem entre os indivíduos.

\subsection{Portais, fluxo de informações e efetividade informacional}

No horizonte da concepção do governo aberto, entende-se que existe ambiente favorável para o tráfego das informações governamentais. Pinho (2008) analisou diversos portais e concluiu que, no tocante à qualidade de comunicação, eles possuem layouts agradáveis, atualizam suas informações com certa frequência e estabelecem bom

Perspectivas em Gestão \& Conhecimento, João Pessoa, v. 8, n. 2, p. 162-178, mai./ago. 2018. 
relacionamento com seus respectivos setores de governo. Conforme o autor, pode-se dizer que existem recursos tecnológicos adequados e boas condições de navegação e de acesso às informações, contudo, ainda persistem situações que persistem a falta de transparência e a impermeabilidade à sociedade civil.

Portanto, os portais estão habilitados a trafegar o fluxo informacional, entendido como o conjunto de informações que são disponibilizadas aos cidadãos e o feedback dos efeitos da informação. Essas informações não podem ser reduzidas à propaganda política ou comercial, apresentando sempre aquilo que é bom ou favorável ao governo e relegando aspectos negativos, e devem ser disponibilizadas em formatos adequados ao usuário e à capacitação do mesmo na construção de significados. É função do Estado garantir o acesso pleno à informação para todos (BORGES; SILVA, 2006).

Akazu e Plínio (2002) argumentam que o governo deve dar plena transparência de suas ações e decisões para que a sociedade possa exercer sua cidadania. Borges e Silva (2006) reforçam a necessidade de disseminação e circulação da informação e de um processo comunicativo de discussão crítica sobre as diferentes questões relativas à construção de uma sociedade mais justa e com maiores oportunidades para todos os cidadãos.

Para que ocorra a efetividade informacional e sejam criados "espaços sociais de cidadania e de transformação" (ARAÚJO, 1999, p. 158) é necessário que a informação possua atributos de objetividade, fidedignidade, relevância, atualização, concisão, interpretabilidade, facilidade de entendimento, acurácia, acessibilidade e segurança e, assim, adquira o status de efetiva.

\section{PROCEDIMENTOS METODOLÓGICOS}

Este estudo se propõe a discutir a efetividade informacional do menu de transparência dos sítios dos órgãos governamentais a partir das variáveis de acesso, conteúdo, estrutura e valor. Para tanto, a pesquisa divide-se em três vertentes: identificação do conteúdo de informações postadas; acesso às opções de navegação do menu; e valor informacional do conteúdo.

Trata-se de uma pesquisa descritiva, pois pretende investigar as características do governo aberto no que tange à transparência das informações (GIL, 2002; HAIR JUNIOR et al., 2007). Adotou-se a estratégia qualitativa para coleta dos dados, ou seja, grupo de foco, surveys de questionários e escalas numéricas (HAIR JUNIOR et al., 2007).

A pesquisa desenvolveu-se com a aplicação de dois questionários distintos. Questionário 1: acessibilidade aos dados de transparência, cujo objetivo foi avaliar a qualidade dos sítios de transparência dos órgãos governamentais no tocante a facilidade de acesso, movimentação, padronização visual, estrutura e acesso às informações e clareza dos ícones. 0 Questionário 2: Enquete sobre Transparência Pública, objetivou avaliar as informações postadas nos sítios de transparência sob o enfoque da estrutura, compreensão, conteúdo, adequação e participação.

Para verificação da confiabilidade interna das escalas utilizadas nos questionários, utilizou-se o coeficiente Alfa de Cronbach. Valores menores que 0,70 indicam consistência interna baixa; valores entre 0,80 e 0,90 indicam boa consistência (STREINER, 2003).

Visando facilitar a interpretação e a avaliação dos quesitos de ambos os questionários, foi aplicada a escala phrase completion, criada por Hodge e Gillespie (2003). Trata-se de um sistema de pontuação de 0 a 10, sendo que $0=$ sem associação com o critério; 1 a $3=$ associação baixa, 4 a 7 = associação razoável; e 8 a 10 = boa associação.

A pesquisa foi realizada no período de três meses e os questionários foram reenviados três vezes eletronicamente.

Perspectivas em Gestão \& Conhecimento, João Pessoa, v. 8, n. 2, p. 162-178, mai./ago. 2018. 


\subsection{Identificação da institucionalização do conteúdo das informações postadas - Análise de Conteúdo}

Utilizaram-se os procedimentos técnicos de pesquisa documental com análise de conteúdo para se avaliar a institucionalização do conteúdo das informações postadas no menu Transparência (BARDIN, 2011; GIL, 2002). Foram selecionadas quarenta organizações públicas, abrangendo-se os poderes Executivo (7), Legislativo (3) e Judiciário (10); o Ministério Público (4); agências governamentais (2); fundações e autarquias (4); e sítios de governos estaduais (10).

Buscou-se identificar e classificar as informações exigidas nos normativos (atos, portarias, decretos) e postadas nos sítios das organizações públicas.

3.2 A navegação no menu Transparência - Questionário 1: Acessibilidade aos Dados da Transparência

Para avaliação da acessibilidade às informações do menu Transparência, utilizou-se a técnica de questionários estruturados (HAIR JUNIOR et al., 2007). O questionário 1: Acessibilidade aos Dados de Transparência foi desenvolvido, pré-testado e validado por especialistas da área de Tecnologia da Informação (TI). O público escolhido para a aplicação do questionário foram desenvolvedores da área de $\mathrm{TI}$ de organizações públicas e privadas distintas. Enviou-se, eletronicamente, os questionários a vinte especialistas.

Avaliaram-se seis critérios a partir da conceituação de acessibilidade descrita na Cartilha de Usabilidade do Ministério do Planejamento, Desenvolvimento e Gestão (2010): "Acessibilidade trata do acesso a locais, produtos, serviços ou informações efetivamente disponíveis ao maior número e variedade possível de pessoas independente de suas capacidades físico-motoras e perceptivas, culturais e sociais". Os critérios foram os seguintes: acesso ao menu Transparência; facilidade de transição nas opções; padronização visual; estrutura das informações; facilidade de compreensão dos ícones; e facilidade de acesso às informações.

Neste tópico da pesquisa, o resultado do cálculo da confiabilidade interna dos questionários foi de 0,89 - dentro dos padrões de boa consistência interna - e obteve-se o percentual de $20 \%$ de respostas aos questionários enviados.

3.3 Valor informacional do conteúdo dos menus de transparência - Questionário 2: Enquete sobre Transparência Pública

Para avaliar as informações postadas a partir das variáveis estrutura, compreensão, conteúdo, adequação e participação, optou-se, por se tratar de um estudo transversal, pela utilização de survey, com questionário estruturado, análise baseada em mensurações estatísticas (médias e frequências) e correlações (HAIR JUNIOR et al., 2007).

O questionário foi desenvolvido no editor Formulários Google, encaminhado para validação por especialista e, posteriormente, pré-testado com servidores públicos. Compôs-se por dois blocos: o primeiro buscou a identificação do respondente (escolaridade, área de atuação, idade, frequência de acesso à transparência); o segundo apresentou seis afirmativas sobre os critérios - linguagem utilizada, relevância das informações, volume, expectativa do respondente com as informações, disposição em participar da tomada de decisão e realização do princípio democrático da transparência.

O público escolhido para a aplicação do questionário foram grupos de pesquisa cadastrados no Diretório dos Grupos de Pesquisa - Plataforma Lattes/CNPq. Inicialmente, enviou-se o questionário para os líderes de 70 grupos, cujas área de pesquisa estivesse relacionada com o tema do artigo. Posteriormente, e buscando aumentar a participação na pesquisa, enviou-se o questionário para 77 pesquisadores participantes de grupos de pesquisas listados na Plataforma Lattes/CNPq. Obteve-se percentual de $18,57 \%$ de respostas. A confiabilidade interna do questionário foi de 0,88 , considerada muito boa.

Perspectivas em Gestão \& Conhecimento, João Pessoa, v. 8, n. 2, p. 162-178, mai./ago. 2018. 


\section{RESULTADOS E DISCUSSÕES}

\subsection{Identificação da institucionalização do conteúdo das informações postadas}

A estrutura das informações é normatizada por cada um dos três poderes pelo Ministério Público e pelos governos dos estados. Foram avaliados nove normativos (com suas alterações posteriores), abrangendo-se todas as entidades propostas pelo estudo, compostas por atos, decretos, leis, manuais e resolução. Contudo, percebeu-se a existência de diversos normativos que vão sendo aperfeiçoados e atualizados.

A normatização alcança diversos tópicos relacionados à gestão administrativa: execução orçamentária e financeira; licitações e contratações; divulgação de salário; atendimento ao cidadão; resultados de programas e ações; legislação; estrutura administrativa; Lei de Acesso à Informação; relatórios de gestão; gestão patrimonial, gestão de pessoas; resultado da atividade fim; governança; e planejamento. Esses tópicos estão presentes em quase todos os normativos analisados, o que demonstra a uniformidade da legislação.

A adequação das disposições normativas às informações efetivamente expostas nos sítios das organizações estudadas não se apresenta de maneira uniforme. Percebe-se que, pelos resultados apresentados a seguir, a escolha da internet como espaço de participação social e de transparência não está sendo efetiva, embora Gomes (2005, p. 67) insista que a internet seja "uma oportunidade, possivelmente inalcançável por outros meios, de disponibilidade, abertura e transparência" e que possibilita "acesso à informação política de toda a natureza, em todos os seus formatos".

Entre $80 \%$ e $100 \%$ dos sítios apresentam informações sobre execução orçamentáriafinanceira e licitações, contratos e convênios; dispõem de canais de atendimento ao cidadão; informam a remuneração dos servidores; e exibem relatórios de gestão e de auditoria. Entre $50 \%$ e $70 \%$ apresentam informações sobre estrutura organizacional, estrutura institucional e gestão de pessoas (estrutura de cargos, concursos, formação, benefícios, atribuição) da organização.

Aproximadamente $46 \%$ das organizações apresentam informações sobre planejamento estratégico e resultados de suas atividades fim. Especificamente, sobre os dez sítios de governos do Estado estudados, identificou-se que $50 \%$ deles não apresentam informações sobre a dívida pública do estado, assunto de interesse da população. A gestão patrimonial, embora importante nas organizações, é pouco apresentada: apenas $21 \%$ das organizações disponibilizam informações e, geralmente, sobre imóveis e veículos. Araújo (1999, p. 155) alerta que o "não-acesso à informação ou ainda o acesso limitado ou o acesso a informações distorcidas dificultam o pleno exercício da cidadania".

Levando-se em consideração os dados apresentados nos sítios estudados, tem-se que o Poder Legislativo e o Ministério Público apresentam a maior gama de informações aproximadamente $85 \%$ e $78 \%$ dos tópicos sugeridos, respectivamente. Os demais sítios apresentam percentuais baixos de volume de informação, exibindo entre $54 \%$ e $61 \%$ dos tópicos sugeridos. Nesse sentido, o espaço democrático pretendido, ou seja, os sítios, não estaria sendo efetivo, pois reduz a possibilidade de participação social por apresentar informações limitadas, conforme evoca Gomes (2005, p. 61): "Efetividade diz respeito à possibilidade de produção de efeitos na esfera da decisão política".

Não obstante os resultados apresentados, deve-se destacar que os sítios dos órgãos vinculados ao Poder Legislativo apresentam informações que remetem, de forma inovadora, à governança pública, assunto bastante atual e de interesse geral. O sítio do Governo do Estado de Minas Gerais apresenta planejamento de forma igualmente inovadora. O sítio do Superior Tribunal de Justiça também merece destaque, com a disponibilização de plano de logística.

Perspectivas em Gestão \& Conhecimento, João Pessoa, v. 8, n. 2, p. 162-178, mai./ago. 2018. 
Essas iniciativas tornam vivas as observações de Vishwanath e Kaufmann (1999, p. 4) quanto à informação ser "de boa qualidade e confiável, oportuna, completa, justa, consistente e representada em termos claros e simples", atributos para a operacionalização da transparência.

\subsection{Acesso às informações e navegação no menu Transparência}

Para a avaliação deste tópico utilizou-se os resultados obtidos com a aplicação do Questionário 1: Acessibilidade aos Dados da Transparência.

Tabela 1 - Navegabilidade, usabilidade e acessibilidade ao menu Transparência Resultado geral (todas as organizações)

\begin{tabular}{l|r|r|r|r}
\hline \multirow{2}{*}{ QUESITOS } & \multicolumn{3}{c}{ ASSOCIAÇÃO } \\
\cline { 2 - 5 } & Inexistente & \multicolumn{1}{c}{ Baixa } & Razoável & \multicolumn{1}{c}{ Boa } \\
\hline Facilidade de acesso ao menu “transparência” & $0 \%$ & $6,19 \%$ & $60,82 \%$ & $32,99 \%$ \\
\hline Facilidade para mudança de áreas dentro do menu & $0 \%$ & $23,71 \%$ & $41,24 \%$ & $35,05 \%$ \\
\hline Padronização visual nas opções de consulta & $0 \%$ & $17,53 \%$ & $59,79 \%$ & $22,68 \%$ \\
\hline Informações estruturadas de forma lógica & $0 \%$ & $13,40 \%$ & $51,55 \%$ & $35,05 \%$ \\
\hline Poucos passos para acessar informações & $0 \%$ & $26,80 \%$ & $44,33 \%$ & $28,87 \%$ \\
\hline Ícones para acesso compreensíveis & $0 \%$ & $38,14 \%$ & $39,18 \%$ & $22,68 \%$ \\
\hline
\end{tabular}

Fonte: elaborado pelo autor (2017)

Os resultados gerais indicam que a navegabilidade e acessibilidade às informações dos menus de transparência são razoáveis - opção de maior percentual em todos os quesitos. 0 fato de nenhum quesito ter sido considerado bom demonstra que os menus de transparência foram considerados instrumentos ineficazes de prestação de informações.

Tem-se, também, que a maior parte dos quesitos obtiveram índices de baixa associação (entre $13 \%$ e $38 \%$ ), o que reforça o argumento de inadequação do instrumento quanto à usabilidade. Usabilidade diz respeito à "aplicação de técnicas que proporcionem a facilidade de uso de um dado objeto [...]. A usabilidade busca assegurar que qualquer pessoa consiga usar o sítio e que este funcione da forma esperada pela pessoa" (BRASIL, 2010), em especial quanto à facilidade de uso, de aprendizado e de memorização de tarefas.

Nesse aspecto, Shannon e Weaver (1964) já demonstravam preocupação com a medição da capacidade de comunicação de determinado canal e da produção de ruídos que afetassem a efetividade da comunicação. A Lei Complementar 101/2000, em vários artigos (arts. 48, 51, 55, 64), determina a divulgação de dados em meios eletrônicos de acesso público, o que não é feito eficazmente, segundo resultados da presente pesquisa. Ainda assim, a prática de divulgação por meio eletrônico é aceita por diversos autores, devido ao fato do acesso ser mais rápido e produtivo, à disponibilização da informação a todos em igualdade de condições, ao maior alcance de cidadãos, ao baixo custo, à remoção de dificuldades relacionadas a tempo e espaço e à interatividade e interação proporcionadas (ARAÚJO, 1999; GOMES, 2015; MEIJER; CURTIN; HILLEBRANDT, 2012; VISHWANATH; KAUFMANN, 1999).

Tabela 2 - Navegabilidade, usabilidade e acessibilidade ao menu Transparência Instituições individualizadas

\begin{tabular}{l|r|r|r|r}
\hline \multirow{2}{*}{ ORGANIZAÇÕES } & \multicolumn{4}{c}{ RESPOSTAS } \\
\cline { 2 - 5 } & Inexistente & \multicolumn{1}{c}{ Baixa } & \multicolumn{1}{c}{ Razoável } & \multicolumn{1}{c}{ Boa } \\
\hline Poder Executivo & $0 \%$ & $22,00 \%$ & $52,67 \%$ & $25,33 \%$ \\
\hline Poder Legislativo & $0 \%$ & $18,18 \%$ & $46,97 \%$ & $34,85 \%$ \\
\hline Poder Judiciário & $0 \%$ & $15,74 \%$ & $60,19 \%$ & $24,07 \%$ \\
\hline Ministério Público & $0 \%$ & $4,76 \%$ & $52,38 \%$ & $42,86 \%$ \\
\hline
\end{tabular}

Perspectivas em Gestão \& Conhecimento, João Pessoa, v. 8, n. 2, p. 162-178, mai./ago. 2018. 


\begin{tabular}{l|r|r|r|r}
\hline Autarquias, Fundações e Agências & $0 \%$ & $12,50 \%$ & $61,67 \%$ & $28,87 \%$ \\
\hline Estados Federados & $0 \%$ & $26,67 \%$ & $51,67 \%$ & $21,67 \%$ \\
\hline
\end{tabular}

Fonte: elaborado pelo autor (2017).

Os resultados demonstram que o menu Transparência do Ministério Público da União possui os melhores índices nas classificações Razoável e Boa $(95,2 \%)$, seguido das autarquias, fundações e agências $(87,5 \%)$ e do Poder Judiciário $(84,2 \%)$. Os sítios dos Estados Federados $(26,67 \%)$ e do Poder Executivo $(22,00 \%)$ apresentam os piores índices para a classificação Baixa.

Os tópicos que obtiveram menores índices na categoria Baixa, por ordem de pontuação, referem-se à identificação visual, navegação e autonomia. Segundo Abrahão, Silvino e Sarmet (2005), quando da concepção de sítios e aplicativos, no desenvolvimento de ações que envolvam usabilidade e navegabilidade, deve-se utilizar a lógica do usuário ao invés da lógica do especialista. Contudo, acredita-se que a interação entre usuário e especialista é superficial. Assim, justificam-se os índices atribuídos a visualização, acesso e navegabilidade.

\subsection{Valor informacional do conteúdo dos menus de transparência}

Para a avaliação deste tópico utilizou-se os resultados obtidos com a aplicação do Questionário 2: Enquete sobre Transparência Pública.

Os pesquisadores respondentes, em sua maioria (76,92\%), possuem doutorado $(57,69 \%)$ e mestrado $(19,23 \%)$, mas há também graduados $(11,54 \%)$ e pós-doutorados $(11,54 \%)$. São atuantes no serviço público federal $(50,00 \%)$, no serviço público estadual $(30,77 \%)$, em organizações privadas $(15,38 \%)$ e em organizações sociais $(3,85 \%)$.

As áreas de pesquisa onde atuam respondentes são várias, o que agregou valor à pesquisa: Direito (23,81\%); Administração, Gestão Pública e Ciência Política (14,29\%); Sociologia e Tecnologia da Informação (9,52\%); e Contabilidade, Arquivologia e Saúde (4,76\%). A maior parte dos participantes da pesquisa acessa os sítios de transparência frequentemente $(80,77 \%)$. O restante acessa os sítios raramente $(19,23 \%)$.

Obteve-se boa representatividade, tendo em vista a amplitude das áreas de atuação e a frequência com que os participantes acessam os portais de transparência. As demais questões do formulário buscaram avaliar os tópicos abaixo relacionados e discutidos.

Quadro 1 - Comparativo da Opinião dos Respondentes por Tipo de Instituição

\begin{tabular}{|l|l|l|l|}
\hline \multirow{2}{*}{ QUESTIONAMENTO } & \multicolumn{3}{|c|}{ INSTITUIÇÃO } \\
\cline { 2 - 4 } & Serviço Público Federal & \multicolumn{1}{|c|}{$\begin{array}{c}\text { Serviço Público } \\
\text { Estadual }\end{array}$} & Iniciativa Privada \\
\hline A linguagem é acessível? & $\begin{array}{l}\text { Parcialmente } \\
\text { verdadeiro }\end{array}$ & $\begin{array}{l}\text { Parcialmente } \\
\text { verdadeiro }\end{array}$ & $\begin{array}{l}\text { Plenamente } \\
\text { verdadeiro }\end{array}$ \\
\hline As informações são relevantes? & $\begin{array}{l}\text { Plenamente } \\
\text { verdadeiro }\end{array}$ & $\begin{array}{l}\text { Plenamente } \\
\text { verdadeiro }\end{array}$ & Não verdadeiro \\
\hline $\begin{array}{l}\text { O volume de informações é } \\
\text { adequado? }\end{array}$ & $\begin{array}{l}\text { Parcialmente } \\
\text { verdadeiro }\end{array}$ & $\begin{array}{l}\text { Parcialmente } \\
\text { verdadeiro }\end{array}$ & Não verdadeiro \\
\hline $\begin{array}{l}\text { Atende as necessidades } \\
\text { individuais de informação? }\end{array}$ & $\begin{array}{l}\text { Parcialmente } \\
\text { verdadeiro }\end{array}$ & $\begin{array}{l}\text { Parcialmente } \\
\text { verdadeiro }\end{array}$ & Não verdadeiro \\
\hline $\begin{array}{l}\text { Desperta o interesse em } \\
\text { participar? }\end{array}$ & Não verdadeiro & $\begin{array}{l}\text { Parcialmente } \\
\text { verdadeiro }\end{array}$ & $\begin{array}{l}\text { Plenamente } \\
\text { verdadeiro }\end{array}$ \\
\hline $\begin{array}{l}\text { Assegura o princípio da } \\
\text { transparência? }\end{array}$ & $\begin{array}{l}\text { Parcialmente } \\
\text { verdadeiro }\end{array}$ & $\begin{array}{l}\text { Parcialmente } \\
\text { verdadeiro }\end{array}$ & Não verdadeiro \\
\hline
\end{tabular}

Fonte: elaborado pelo autor (2017)

Perspectivas em Gestão \& Conhecimento, João Pessoa, v. 8, n. 2, p. 162-178, mai./ago. 2018. 
Percebe-se que os respondentes que atuam em instituições públicas federais e estaduais possuem concepções bem próximas e mais favoráveis, enquanto a iniciativa privada apresenta concepções bastante desfavoráveis.

\begin{abstract}
A ciência da comunicação nos ensina que definir os usuários como massa (cidadãos) não é útil. Deve-se reconhecer que há um grupo diversificado de usuários individuais e organizados com capacidades e interesses variados. A visão e a voz nunca são criadas igualmente para este grupo, já que alguns aproveitam melhor as oportunidades do que outros. Os governos podem ser tentados a definir a informação que o "usuário geral" deseja e perder os efeitos que isso tem sobre os vários grupos de usuários. Alguns usuários podem precisar de acesso a um conjunto de dados completos para poderem realizar suas próprias análises, outros podem ser servidos melhor com a apresentação de dados em um formato mais facilmente acessível. O governo aberto deve basear-se numa estratégia de comunicação adaptada ao domínio dos potenciais utilizadores. (MEIJER; CURTIN; HILLEBRANDT, 2012, p. 18).
\end{abstract}

\title{
4.3.1 Discussão das questões 1 a 3
}

Questão 1: As informações estão colocadas em linguagem de fácil entendimento

Resultado: A maior parte dos respondentes $(86,26 \%)$ entende que essa afirmativa é parcialmente verdadeira $(57,69 \%)$ ou plenamente verdadeira $(28,57 \%)$.

Questão 2: As informações são relevantes e importantes para o entendimento das ações dos órgãos públicos

Resultado: A maioria dos participantes $(76,93 \%)$ acredita que a afirmativa é parcialmente verdadeira $(34,62 \%)$ ou plenamente verdadeira $(42,31 \%)$.

Questão 3: O volume de informações é adequado à necessidade que um cidadão pode ter para conhecer a atuação governamental

Resultado A maior parte das respostas indica que o volume de informações é parcialmente adequado $(57,69 \%)$, enquanto outra parte significativa aponta que o volume não é adequado (26,92\%).

As respostas a esses três questionamentos atestaram que as informações levadas aos cidadãos gozam de relevância, inteligibilidade e bom volume. Para que a informação tenha bom uso, é necessário que haja extensão, acessibilidade, relevância, qualidade (GOMES, 2005; VISHWANATH; KAUFMANN, 1999), inexistência de ruídos e bom canal de comunicação (SHANNON; WEAVER, 1964).

\subsubsection{Discussão das questões 4 e 5}

Questão 4: As informações publicadas atendem à necessidade de conhecimento das ações governamentais

Resultado: Essa assertiva é parcialmente verdadeira para $53,85 \%$ dos participantes e não é verdadeira para $30,77 \%$.

Questão 5: As informações postadas despertam o interesse em participar do processo de tomada de decisão

Perspectivas em Gestão \& Conhecimento, João Pessoa, v. 8, n. 2, p. 162-178, mai./ago. 2018. 
Resultado: Os respondentes postulam que as informações não despertam o interesse em participar das decisões governamentais $(50,00 \%)$ ou despertam esse interesse parcialmente $(30,77 \%)$.

Pelas respostas a essas duas questões, percebe-se que as informações apresentadas nos portais de transparência não produzem o efeito esperado, ou seja, não fomentam a participação cidadã nas tomadas de decisão dos governantes.

Informação é a base com a qual o público pode seguir os negócios do Estado e conhecer os seus direitos. Novelli (2006) esclarece que o processo de comunicação entre as instituições públicas e a sociedade tem como objetivo promover a troca e o compartilhamento de informações. Segundo Araújo (1999, p. 158), "as possibilidades de transformação via informação se iniciam na prática informacional da recepção". A participação cidadã (informação e colaboração) na produção de políticas públicas pode aumentar a sua eficiência e eficácia (ZÁRATE, 2010). A informação permite ao público acompanhar as ações do Estado e, assim, manifestar-se e provocar a adaptação dos planos de governo (LOISIER; COSSETTE, 1993).

De acordo com Gomes (2005, p. 59), os requisitos básicos para o desenvolvimento da participação democrática são:

[...] volume adequado de conhecimento político estrutural e circunstancial, estoque apropriado de informações não-distorcidas e relevantes, suficientes para habilitar o cidadão a níveis adequados de compreensão de questões, argumentos, posições e matérias relativas aos negócios públicos e ao jogo político.

\subsubsection{Discussão da questão 6}

Questão 6: As informações postadas tornam real o princípio democrático da transparência Resultado: Essa afirmativa é parcialmente verdadeira para 53,85\% dos participantes e não verdadeira para $26,92 \%$, expondo a fragilidade de realização do princípio.

Segundo Matias-Pereira (2002, p. 2), "a transparência do Estado se efetiva por meio do acesso do cidadão à informação governamental, o que torna mais democrática a relação entre - Estado e a sociedade civil", e a "democratização do Estado tinha como um dos seus pressupostos o controle do seu aparelho pela sociedade civil. Para tal, a transparência do Estado, expressa na possibilidade de acesso do cidadão à informação governamental, constituía um requisito fundamental". Vishwanath e Kaufmann (1999) entendem que a transparência é essencial para a economia, pois melhora a alocação de recursos, aumenta a eficiência, as perspectivas de crescimento (em sentido contrário às imperfeições de informação) e os custos de transação e provoca falhas de mercado. Piotrowski e Van Ryzin (2007, p. 306) relatam que "os dados e análises sugerem que há várias dimensões para a demanda de transparência do público, incluindo preocupações fiscais, de segurança e governamentais, e abertura de princípios".

\section{CONSIDERAÇÕES FINAIS}

Retornando ao objetivo da pesquisa: buscou-se verificar se os dados postados nos sítios de transparência governamental atendem às preferências do cidadão e despertam o interesse deste em participar das decisões políticas. A utilização de um modelo operacional que permita ao cidadão-usuário obter as informações que deseja e, constatando nessas informações condições de efetividade, serão criados espaços de participação social que proporcionam o desenvolvimento e aperfeiçoamento das políticas públicas.

Perspectivas em Gestão \& Conhecimento, João Pessoa, v. 8, n. 2, p. 162-178, mai./ago. 2018. 
As descobertas apresentadas são relevantes porque demonstraram que, mesmo os menus de transparência sendo considerados razoáveis, os percentuais de "ruim" ou "não se adequam" são muito elevados. Destaque negativo são os sítios dos estados federados, que carecem de avanços consideráveis para verdadeiramente serem transparentes, bem como as melhorias que devem ser introduzidas nos portais do Poder Executivo.

A pesquisa apontou a necessidade de normatização superior do conteúdo e da forma dos menus de transparência. Embora existam diversos menus bastante semelhantes, algumas informações importantes são negligenciadas, como os resultados das ações das organizações, a efetividade de programas e políticas públicas, o alcance de metas físicas, a gestão patrimonial (bens) e a gestão de pessoas.

De forma conclusiva, o estudo demonstrou que as informações postadas nos sítios de transparência não fomentam o interesse do cidadão em participar do processo decisório governamental. Sendo essa a intenção central do processo informacional, conclui-se que diversas mudanças devem ser implementadas nos portais para que as informações se tornem úteis e modifiquem a atuação dos cidadãos. Também, percebe-se pelo estudo que a efetividade informacional está comprometida, pois não dispõe plenamente dos atributos de relevância, adequação e facilidade de entendimento.

A correção dos problemas identificados no estudo reivindica abordagem da informação acima da compreensão convencional. Deve-se passar ao patamar do planejamento da comunicação pública de forma ampla, inclusiva e que fomente a participação.

Concluída a pesquisa, admite-se que os objetivos foram alcançados e poderão contribuir para o aprimoramento do instrumento de transparência em uso com as evidências apresentadas e a base teórica explorada. A exploração que a pesquisa possibilitou a partir das opiniões de especialistas na área de $\mathrm{TI}$ e de grupos de pesquisa permite sugerir novos estudos que busquem a opinião dos cidadãos quanto ao tema e meçam a efetividade dos portais sobre o enfoque da participação social e da accountability dos governantes.

\section{REFERÊNCIAS}

AKUTSU, L.; PINHO, J. A. G. Sociedade da Informação, accountability e democracia delegativa: Investigação em portais de governo no Brasil. Revista de Administração Pública, Rio de Janeiro, v. 36, n. 5, set./out 2002. Disponível em: http://www.ipea.gov.br/participacao/images/pdfs/democraciadigital/borgessilva2006.pdf. Acesso em: 18 fev. 2018.

ABRAHÃO, J. I.; SILVINO, A. M. D.; SARMET, M. M. E. Cognição e trabalho informatizado. Psicologia: Teoria e Pesquisa, Brasília, v. 21, n. 2, p. 163-171, maio/ago. 2005. Disponível em: http://www.scielo.br/pdf/ptp/v21n2/a06v21n2.pdf. Acesso em: 15 fev. 2017.

ARAÚJO, E. A. Informação, sociedade e cidadania: Gestão da informação no contexto de organizações não-governamentais (ONGs) brasileiras. Ciência da Informação, Brasília, v. 29, n. 2, p. 155-167, maio/ago. 1999.1 Disponível em: http://www.scielo.br/pdf/ci/v28n2/28n2a08.pdf. Acesso em: 12 nov. 2016.

BORGES, J.; SILVA, H. P. Democracia eletrônica e competência informacional. Informação \& Sociedade, João Pessoa, PB, v. 16, n. 1, 129-137, jan./jul. 2006. Disponível em: http://www.ipea.gov.br/participacao/images/pdfs/democraciadigital/borgessilva2006.pdf. Acesso em: 18 fev. 2018.

BRASIL. Câmara dos Deputados. Ato no 45, de 16 de julho de 2012. Dispõe sobre a aplicação, no âmbito da Câmara dos Deputados, da Lei de Acesso à Informação - Lei no 12.527, de 18 de

Perspectivas em Gestão \& Conhecimento, João Pessoa, v. 8, n. 2, p. 162-178, mai./ago. 2018. 
novembro de 2011, e dá outras providências. Site da Câmara dos Deputados. Disponível em: http://www2.camara.leg.br/legin/int/atomes/2012/atodamesa-45-16-julho-2012-773823norma-cd-mesa.html. Acesso em: 16 nov. 2016.

BRASIL. Conselho Nacional de Justiça - CNJ. Resolução n. 102, de 15 de dezembro de 2009. Dispõe sobre a regulamentação da Publicação de informações alusivas à gestão orçamentária e financeira, aos quadros de pessoal e respectivas estruturas remuneratórias dos tribunais e conselhos. Diário Oficial da União, Poder Judiciário Federal, Brasília, DF, 2009. Disponível em: http://www.cnj.jus.br/files/atos administrativos/resoluo-n102-15-12-2009-presidncia.pdf. Acesso em: 18 fev. 2018.

BRASIL. Conselho Nacional do Ministério Público - CNMP. Manual de Transparência do Ministério Público. 4. Ed. Brasília: Ministério Público, 2016. Disponível em: http://www.cnmp.mp.br/portal/publicacoes/245-cartilhas-e-manuais/9689-manual-do-portalda-transparencia-4-edicao. Acesso em: 18 fev. 2018.

BRASIL. Constituição da República Federativa do Brasil de 1988. Site do Planalto. Disponível em: http://www.planalto.gov.br/ccivil 03/constituicao/constituicaocompilado.htm. Acesso em: 15 nov. 2016.

BRASIL. Decreto n. 7.724, de 16 de maio de 2012 (2016). Dispõe sobre os procedimentos do Poder Executivo, que garante o acesso à informação, nos termos da legislação vigente. Site do Planalto. Disponível em: http://www.planalto.gov.br/ccivil 03/ ato20112014/2012/decreto/d7724.htm. Acesso em: 18 fev. 2018.

BRASIL. Lei Complementar n. 101, de 4 de maio de 2000. Estabelece normas de finanças públicas voltadas para a responsabilidade na gestão fiscal e dá outras providências. Diário Oficial da União, Presidência da República, Brasília, DF, 2000. Disponível em: http://www.planalto.gov.br/ccivil 03/Leis/LCP/Lcp101.htm. Acesso em: 18 fev. 2018.

BRASIL. Lei n. 12.527, de 18 de novembro de 2011. Regula o acesso a informações previsto no inciso XXXIII do art. 50, no inciso II do § 3 o do art. 37 e no § 2 을 do art. 216 da Constituição Federal; altera a Lei no 8.112, de 11 de dezembro de 1990; revoga a Lei no 11.111, de 5 de maio de 2005, e dispositivos da Lei no 8.159, de 8 de janeiro de 1991; e dá outras providências. Diário Oficial da União, Presidência da República, Brasília, DF, 2011. Disponível em: http://www.planalto.gov.br/ccivil 03/ ato2011-2014/2011/lei/l12527.htm. Acesso em: $18 \mathrm{fev}$. 2018.

BRASIL. Ministério da Transparência e Controladoria-Geral da União. 2a Plano de ação brasileiro para o governo aberto. Brasília: Ministério da Transparência, Fiscalização e Controladoria-Geral, 2013. Disponível em: http://www.governoaberto.cgu.gov.br/central-deconteudo/documentos/arquivos/2-plano-acao-brasil-2013-15.pdf. Acesso em: 18 fev. 2016.

BRASIL. Ministério da Transparência e Controladoria-Geral da União. Guia de publicação ativa nos sítios eletrônicos dos órgãos e entidades do Poder Executivo Federal. 3. ed. Brasília: Poder Executivo Federal, 2015. Disponível em: http://www.acessoainformacao.gov.br/lai-parasic/sic-apoio-orientacoes/guias-e-orientacoes/guia 3a-versao-publicado-agosto-2015.pdf. Acesso em: 16 nov. 2016.

BRASIL. Ministério do Planejamento, Orçamento e Gestão - MPOG. Padrões Web em Governo Eletrônico e-PWG: Cartilha de usabilidade. Versão 1.2. Brasília: Poder Executivo Federal, 2010. Disponível em: http://epwg.governoeletronico.gov.br/cartilha-usabilidade\#s2F. Acesso em: 24 nov. 2016.

Perspectivas em Gestão \& Conhecimento, João Pessoa, v. 8, n. 2, p. 162-178, mai./ago. 2018. 
BRASIL. Senado Federal. Ato no 9, de 16 de maio de 2012. Regulamenta, no âmbito do Senado Federal, a Lei no 12.527, de 18 de novembro de 2011, que dispõe sobre o acesso aos dados, informações e documentos de interesse da sociedade e do Estado. Boletim Administrativo Eletrônico de Pessoal, no 4976, de 17 de maio de 2016. Disponível em: https://www12.senado.leg.br/institucional/arquivo/arquivos-pdf/atc-09-2012. Acesso em: 12 out. 2016.

BRASIL. Senado Federal. Ato no 10, de 30 de julho de 2012. Dispõe sobre a forma de divulgação no Portal da Transparência do Senado Federal das informações relativas ao subsídio e à remuneração recebidos por senadores e servidores ativos, respectivamente. Boletim Administrativo Eletrônico de Pessoal, no 5027, de 30 de julho de 2012. Disponível em: https://www12.senado.leg.br/transparencia/leg/pdf/normas/ato-do-1o-secretario-no-10-de2012.pdf. Acesso em: 12 out. 2016.

BARDIN, Laurence. Análise de Conteúdo. Tradução de Luís Antero Reto e Augusto Pinheiro. São Paulo: Edições 70, 2011.

CADDY, Joanne; VERGEZ, Christian. Information, consultation and public participation in policymaking: Building open government in OECD member countries. In: (Org.). Open government: Fostering dialogue with civil society. France: OECD Publications, 2003. p. 9-23.

CALDERON, César; LORENZO, Sebastian. Introducción. In: Gobierno abierto. Acalá la Real, ESP: Algón Editores, 2010. p. 11-19.

(Org.). Open government:

CURTIN, Deirdre; MENDES, Joana. Transparence et participation: Des principes démocratiques pour l'administration de l'union européenne. Revue française d'administration publique, Paris, n. 1, p. 101-121, 2011. Disponível em: http://www.cairn.info/revue-francaise-dadministration-publique-2011-1-page-101.htm. Acesso em: 15 nov. 2016.

DANCEY, Christine; REYDE, John. Estatística sem matemática para psicologia: Usando SPSS para Windows. Tradução de Luiz Viali. 3 ed. Porto Alegre: Artmed, 2006.

GIL, Antonio Carlos. Como elaborar projetos de pesquisa. 4. ed. São Paulo: Atlas, 1991.

GOMES, Carlos Orta. ¿Transparência? In: CALDERON, César; LORENZO, Sebastian (Coord.). Open government: Gobierno aberto. Acalá la Real, ESP: Algón Editores, 2010. p. 75-86.

GOMES, Wilson. Internet e participação política em sociedades democráticas. Revista Famecos, Porto Alegre, n. 27, p. 58-78, ago. 2005. Disponível em: http://revistaseletronicas.pucrs.br/ojs/index.php/revistafamecos/article/viewFile/3323/2581.

Acesso em: 14 nov. 2016.

HAIR JUNIOR, Joseph; BABIN, Barry; MONEY, Arthur; SAMOUEL, Phillip. Fundamentos de métodos de pesquisa em Administração. Tradução de Lene Belon Ribeiro. Porto Alegre: Bookman, 2007.

HODGE, David; GILLESPIE, David. Phrase completion: An alternative to Likert scales. Social Work Research, Oxford, v. 27, n. 1, p. 45-55, mar. 2003. Disponível em: https://www.researchgate.net/publication/234692602 Phrase Completions An Alternative to Likert Scales. Acesso em: 16 fev. 2018.

JARAMILLO, Juan. Propuesta generale de comunicación pública. Strategy \& Management Business Review, Bogotá, v. 3, n. 2, p. 1-17, 2012. Disponível em: http://www.exeedu.com/publishing.cl/strategy manag bus rev/2012/Vol3/Nro2/1-SM17-11full.pdf. Acesso em: 9 fev. 2017.

Perspectivas em Gestão \& Conhecimento, João Pessoa, v. 8, n. 2, p. 162-178, mai./ago. 2018. 
KUNSCH, Margarida Maria Krohling. Comunicação pública: Direitos de cidadania, fundamentos e práticas. In: MATOS, Heloisa (Org.). Comunicação Pública: Interlocuções, interlocutores e perspectivas. São Paulo: ECA/USP (versão e-book), 2012. p. 13-30. Disponível em: https://goo.gl/mTXMYp. Acesso em: 10 fev. 2017.

LOISIER, Jean; COSSETTE, Marie-Nicole. Communication publique et processus démocratique. Administration Publique du Canada, Toronto, v. 36, n. 2, pp. 263-284, jun. 1993. Disponível em: http://onlinelibrary.wiley.com/doi/10.1111/j.1754-7121.1993.tb00725.x/abstract. Acesso em: $10 \mathrm{fev}, 2017$.

MATIAS-PEREIRA, José. Reforma do Estado e transparência: Estratégias de controle da corrupção no Brasil. In: CONGRESO INTERNACIONAL DEL CENTRO LATINOAMERICANO DE ADMINISTRACIÓN PARA EL DESAROLLO, 7, 2002, Lisboa. Anais... Lisboa: CLAD, 2002.

MEIJER, Albert Jacob; CURTIN, Deirdre; HILLEBRANDT, Maarten. Open government: Connecting vision and voice. International Revew of Administrative Sciences, Londres, v. 78, n. 1, pp. 10-29, mar, 2012. Disponível em: http://ras.sagepub.com/content/78/1/10. Acesso em: 17 nov. 2016.

NOVELLI, Ana Lúcia Coelho Romero. O papel institucional da comunicação pública para o sucesso da governança. Revista Organicom, São Paulo, v. 3, n. 4, p. 75-59, 2006. Disponível em: $\quad$ http://www.revistaorganicom.org.br/sistema/index.php/organicom/article/view/56. Acesso em: fev. 2017.

PINHO, José Antonio Gomes. Investigando portais de governo eletrônico de estados no Brasil: Muita tecnologia, pouca democracia. Revista de Administração Pública, Rio de Janeiro, v. 42, n. 3, p. 471-493, maio/jun. 2008. Disponível em: http://www.scielo.br/pdf/rap/v42n3/a03v42n3. Acesso em: 18 fev. 2018.

PIOTROWSKI, Suzanne; Van RYZIN, Greg. Citizen atitudes toward transparency in local government. The American Review of Public Administration, Londres, v. 73, n. 3, p. 306-323, set. 2007. Disponível em: http://journals.sagepub.com/doi/abs/10.1177/0275074006296777. Acesso em: 15 nov. 2016.

SANTOS, Cássia Dias; VALENTIM, Marta Lígia Pomim. As interconexões entre a gestão da informação e a gestão do conhecimento para o gerenciamento dos fluxos informacionais. Perspectiva em Gestão \& Conhecimento, João Pessoa, PB, v. 4, n. 4, p. 19-33, jul./dez. 2014. Disponível em: https://repositorio.unesp.br/handle/11449/114790. Acesso em: 18 fev. 2018.

SHANNON, Claude; WEAVER, Warren. The mathematical theory of communication. UrbanaChampaign, IL, USA: The University of Illinois, 1964.

STREINER, David. Being inconsistent about consistency: When coefficient alpha does and doesn't matter. Journal of Personality Assessment, London, v. 80, p. 217-222, 2003. Disponível em: https://www.researchgate.net/publication/10745530. Acesso em: 3 fev, 2017.

VISHWANATH, Tara; KAUFMANN, Daniel. Towards transparency in finance and Governance. The World Bank, New York, p. 1-30, set. 1999. Disponível em: http://papers.ssrn.com/sol3/paperscfm?abstract id=258978. Acesso em: 15 nov. 2016.

ZÁRATE, Alberto Ortiz. ¿Por qué esta obsesión con la participación ciudadana? In: CALDERON, César; LORENZO, Sebastian (Coord.). Open government: Gobierno aberto. Acalá la Real, ESP: Algón Editores, 2010. p. 29-49.

Artigo recebido em 21/03/2017 e aceito para publicação em 02/06/2018

Perspectivas em Gestão \& Conhecimento, João Pessoa, v. 8, n. 2, p. 162-178, mai./ago. 2018. 